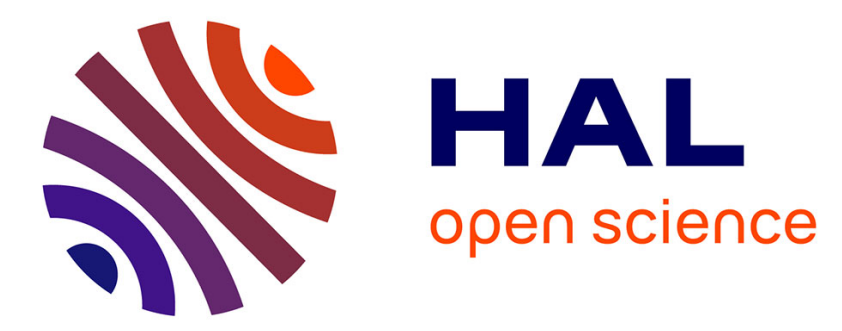

\title{
Load partitioning and evidence of deformation twinning in dual-phase fine-grained $\mathrm{zr}-2.5 \% \mathrm{Nb}$ alloy.
}

Ondrey Muransky, M.R Daymond, Dhriti Bhattacharyya, Olivier Zanellato, S.C Vogel, Lydon.E Edwards

\section{- To cite this version:}

Ondrey Muransky, M.R Daymond, Dhriti Bhattacharyya, Olivier Zanellato, S.C Vogel, et al.. Load partitioning and evidence of deformation twinning in dual-phase fine-grained $\mathrm{zr}-2.5 \% \mathrm{Nb}$ alloy.. Materials Science and Engineering: A, 2013, 564, pp.548-558. 10.1016/j.msea.2012.11.075 . hal-00986463

\section{HAL Id: hal-00986463 https://hal.science/hal-00986463}

Submitted on 6 May 2014

HAL is a multi-disciplinary open access archive for the deposit and dissemination of scientific research documents, whether they are published or not. The documents may come from teaching and research institutions in France or abroad, or from public or private research centers.
L'archive ouverte pluridisciplinaire HAL, est destinée au dépôt et à la diffusion de documents scientifiques de niveau recherche, publiés ou non, émanant des établissements d'enseignement et de recherche français ou étrangers, des laboratoires publics ou privés. 


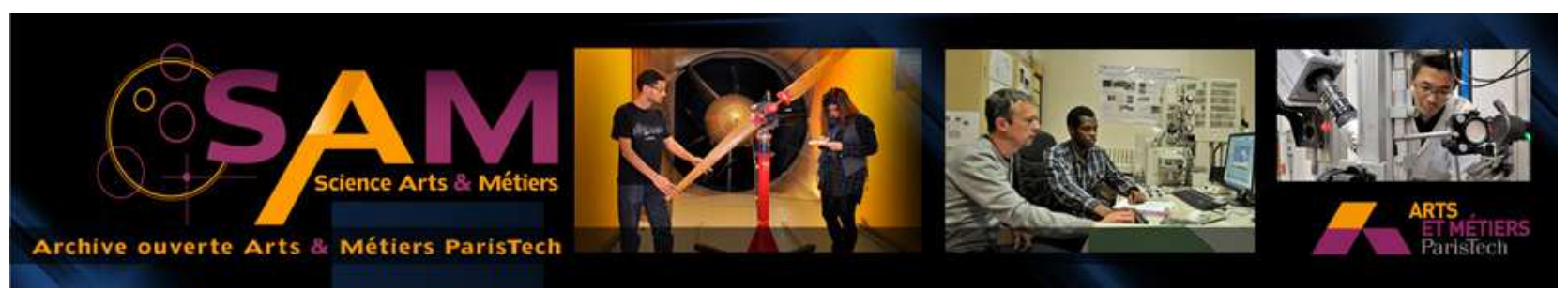

Science Arts \& Métiers (SAM)

is an open access repository that collects the work of Arts et Métiers ParisTech researchers and makes it freely available over the web where possible.

This is an author-deposited version published in: http://sam.ensam.eu

Handle ID: .http://hdl.handle.net/10985/8074

\section{To cite this version :}

Ondrey MURANSKY, Mark.R DAYMOND, Dhriti BHATTACHARYYA, Olivier ZANELLATO, Sven.C VOGEL, Lydon.E EDWARDS - Load partitioning and evidence of deformation twinning in dual-phase fine-grained zr-2.5\%Nb alloy. - Materials Science \& Engineering A - Vol. 564, p.548$558-2013$ 


\title{
Load partitioning and evidence of deformation twinning in dual-phase fine-grained $\mathrm{Zr}-2.5 \% \mathrm{Nb}$ alloy
}

\author{
O. Muránsky ${ }^{\mathrm{a}, *}$, M.R. Daymond ${ }^{\mathrm{b}}$, D. Bhattacharyya ${ }^{\mathrm{a}}$, O. Zanellato $^{\mathrm{c}}$, S.C. $_{\text {Vogel }}^{\mathrm{d}}$, L. Edwards ${ }^{\mathrm{a}}$ \\ a Institute of Material Engineering, ANSTO, Locked Bag 2001, Kirrawee DC, 2234 NSW, Australia \\ ${ }^{\mathrm{b}}$ Department of Mechanical and Materials Engineering, Queen's University, Kingston, Ontario, Canada K7L3N6 \\ ' PIMM, Cnam UMR 8006, 151 Bd de l'Hôpital, F-75013 Paris, France \\ ${ }^{\mathrm{d}}$ Los Alamos Science Center, LANL, Los Alamos, NM 87545, USA
}

Keywords:

$\mathrm{Zr}-2.5 \% \mathrm{Nb}$

Deformation twinning

Load partitioning

Neutron diffraction

TEM

\begin{abstract}
In situ neutron diffraction loading experiments were carried out on a cold-rolled dual-phase ( $\alpha$-phase, $\sim 10 \% \beta$-phase) $\mathrm{Zr}-2.5 \% \mathrm{Nb}$ alloy at room temperature. The specimens were cut at different angles from the rolling direction (RD) towards the transverse direction (TD), thus the loading axis changes gradually from the rolling to transverse direction. Due to the strong texture of the studied alloy, and unidirectional nature of deformation twinning, the changing loading direction with respect to initial texture has a significant impact on the collaborative slip-twinning deformation mode in the hexagonal close-packed $(h c p) \alpha$-phase. The present neutron diffraction results provide direct evidence of $\{1-1.2\}\langle 1-1 .-1\rangle$ "tensile" twins in the $\alpha$-phase of dual-phase $\mathrm{Zr}-2.5 \% \mathrm{Nb}$ alloy at room temperature. Additionally, TEM analysis was employed to confirm the presence of "tensile" twins, and determine if other type of twins were present. It is further clear from the neutron diffraction results that applied load is gradually transferred from the plastically softer $\alpha$-phase to the plastically harder $\beta$-phase which acts as a reinforcing phase having a yield strength in the range 750-900 MPa depending on the loading direction.
\end{abstract}

\section{Introduction}

In its pure form zirconium exhibits a hexagonal close-packed (hcp) $\alpha$-phase which is stable at low temperatures, and a bodycentered cubic (bcc) $\beta$-phase stable at elevated temperatures. Alloying elements affect the relative stability of the phases at a given temperature, and can produce a two phase $(\alpha+\beta)$ regime at intermediate temperatures. In the $\mathrm{Zr}-\mathrm{Nb}$ binary phase diagram (Fig. 1 ) in the vicinity of the $\alpha / \beta$ transus is a monotectoid with the monotectoid reaction at about $600{ }^{\circ} \mathrm{C}$ and $\sim 20 \mathrm{wt} \% \mathrm{Nb}$. Thus for the $\mathrm{Zr}-\mathrm{Nb}$ binary system with more than $\sim 0.6 \mathrm{wt} \%$ but less than $20 \mathrm{wt} \% \mathrm{Nb}$ present, on cooling from the high temperature $\beta$-phase, there is precipitation of $\alpha$-phase below the $\beta \rightarrow \alpha+\beta$ phase transition $\left(\sim 860^{\circ} \mathrm{C}\right.$ for $\left.2.5 \% \mathrm{Nb}\right)$ [1]. At temperatures below $600{ }^{\circ} \mathrm{C}$, monotectoid decomposition occurs under equilibrium conditions and the remaining $\beta$-phase transforms to hcp $\alpha$-phase. However, this reaction is very slow and thus at room temperature the material typically consists of $\alpha$-phase and metastable $\beta$-phase, with the $\mathrm{Nb}$ mostly in the $\beta$-phase. The $\mathrm{Nb}$ content in the $\alpha$-phase is $\sim 0.6 \mathrm{wt} \%$, while in the $\beta$-phase it is $\sim 20 \mathrm{wt} \%$. Due to good

\footnotetext{
* Corresponding author. Tel.: +612 9717 3488; fax: +6129543 7179.

E-mail address: ondrej.muransky@ansto.gov.au (O. Muránsky).
}

mechanical strength, high corrosion and creep resistance, combined with low neutron absorption, $\mathrm{Zr}$ based alloys are used extensively in nuclear power applications. For example, dual-phase $\mathrm{Zr}-2.5 \% \mathrm{Nb}$ with the equilibrium volume fraction of $\beta$-phase of about $10 \%$ is used, among other things, as the pressure tube material for CANada Deuterium Uranium (CANDU) reactors [2]. It is, thus, important to understand the fundamentals of deformation mechanisms in these alloys.

The $h c p$ crystal lattice of $\alpha$-phase, akin to other $h c p$ metals (e.g. $\mathrm{Mg}, \mathrm{Ti}, \mathrm{Be}$ ), has a limited number of independent and readily activated slip systems [3]. It is well-known that while the strain along the crystallographic $\langle a\rangle$ direction can be easily accommodated by slip of $\langle a\rangle$ dislocations on basal, prismatic or pyramidal planes, the slip of $\langle c+a\rangle$ dislocations is restricted to pyramidal slip, leaving this the only slip system able to accommodate strain along the crystallographic $\langle c\rangle$ direction. Hence, the presence of deformation twinning which can readily accommodate plastic strain along the crystallographic $\langle c\rangle$ direction is vital to overall plasticity [4,5]. The hcp metals, thus typically deform by a collaborative twin - dislocation slip deformation mechanism [6]. The most frequently observed twin systems in $\mathrm{Zr}$ and its alloys are $\{1-1.2\}\langle 1-1 .-1\rangle,\{11.1\}$ $\langle 11 .-6\rangle$ "tensile" twinning modes (accommodating $c$-axis elongation), and $\{11 .-2\}\langle 11 .-3\rangle$ "compression" twinning mode (accommodating $c$-axis contraction) $[3,7,8]$. Due to the unidirectional nature 
of deformation twinning, the onset of twinning, and hence overall plasticity is strongly affected by the crystallographic texture. The situation is further complicated in $\mathrm{Zr}-2.5 \% \mathrm{Nb}$ alloy by the presence of about $10 \%$ of bcc Nb-rich $\beta$-phase. Cai et al. $[9,10]$ have studied the load partition between $\alpha$-phase and $\beta$-phase in a moderately textured

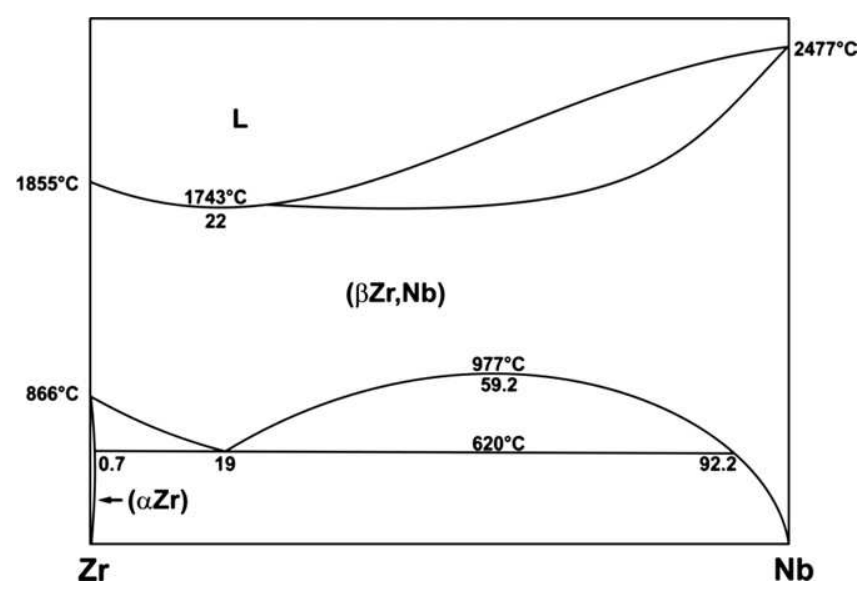

Fig. 1. $\mathrm{Zr}-\mathrm{Nb}$ binary phase diagram.
$\mathrm{Zr}-2.5 \% \mathrm{Nb}$ alloy, however, they did find not any evidence of deformation twinning in the $\alpha$-phase.

The present work discusses in detail the neutron diffraction data obtained during in situ loading of cold-rolled $\mathrm{Zr}-2.5 \% \mathrm{Nb}$ alloy at room temperature. The work focuses on the load partition between the $\alpha$-phase and $\beta$-phase and deformation twinning upon straining. The load partitioning and the onset of deformation twinning are studied with respect to the initial texture, where the loading axis is gradually changing from the rolling direction (RD) towards the transverse direction (TD). The present results provide a first demonstration of twinning in a dual phase $\mathrm{Zr}-2.5 \% \mathrm{Nb}$ alloy at room temperature.

\section{Experimental details}

\subsection{Material}

\subsubsection{Samples}

A cold-rolled sheet of dual-phase $\mathrm{Zr}-2.5 \% \mathrm{Nb}(2.55 \mathrm{wt} \% \mathrm{Nb}$, $0.6 \mathrm{wt} \% \mathrm{Fe},<1200 \mathrm{ppm} \mathrm{O}$, balance $\mathrm{Zr}$ ), alloy was used in the current work. The $4 \times 4 \times 8 \mathrm{~mm}^{3}$ samples were wire-cut from the $50 \times 160 \times 4 \mathrm{~mm}$ cold-rolled sheet in the RD-TD plane, at the following angles: $0^{\circ}, 22.5^{\circ}, 45^{\circ}, 67.5^{\circ}$ and $90^{\circ}$ from rolling
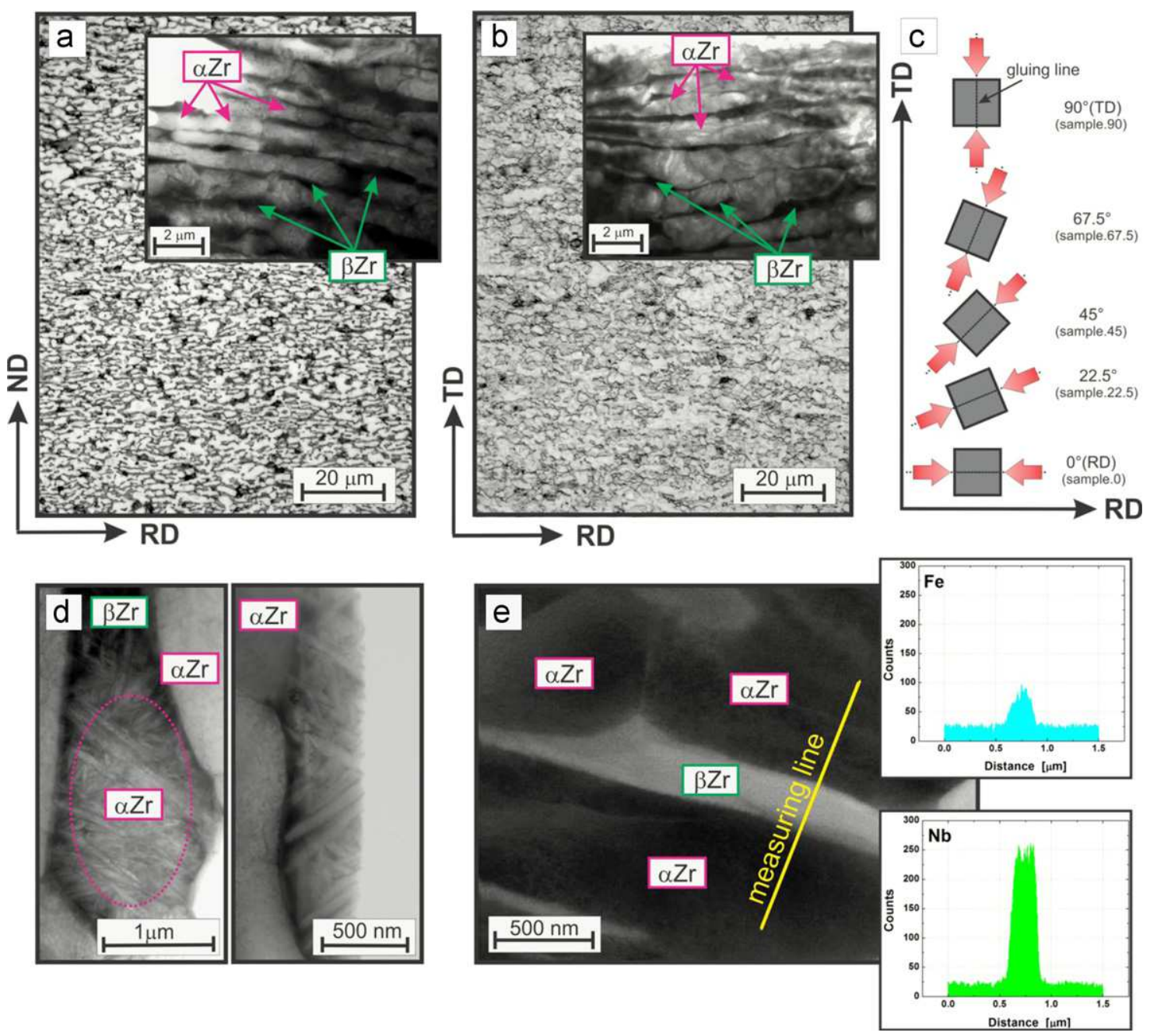

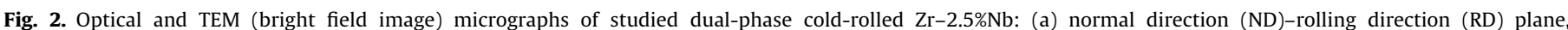

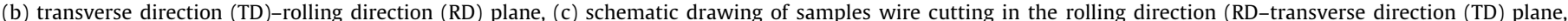

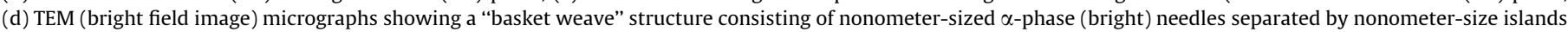

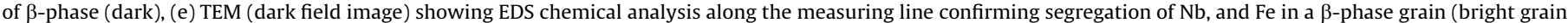
in the middle surrounded by dark $\alpha$-phase grains). 
direction (RD) towards transverse direction (TD), see schematic drawing in Fig. 2c. Four $4 \times 4 \times 8 \mathrm{~mm}^{3}$ samples were then glued together to build a more bulky $8 \times 8 \times 8 \mathrm{~mm}^{3}$ testing

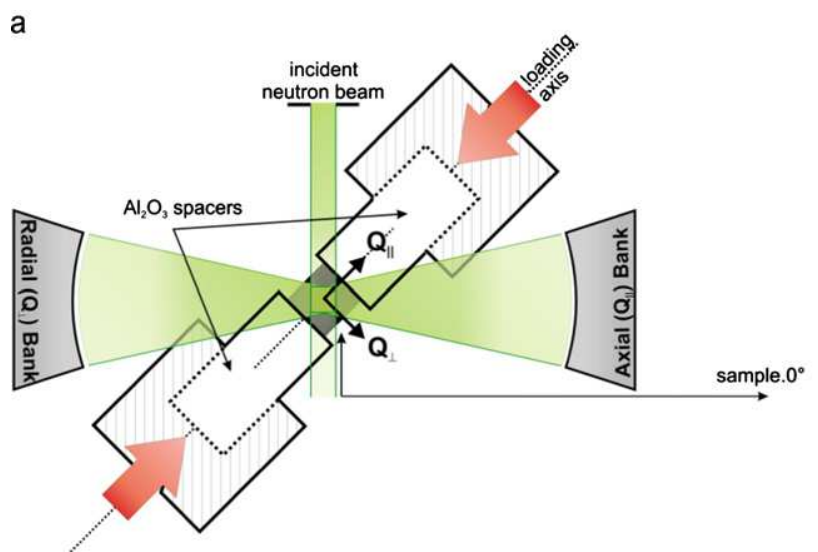

specimen in order to avoid sample buckling and long neutron diffraction counting times, because of the small scattering volume, see Fig. 3.

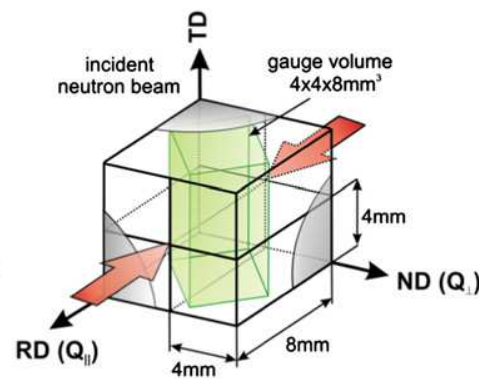

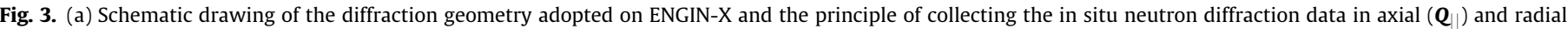
$\left(\boldsymbol{Q}_{\perp}\right)$ detector banks. (b) Test $8 \times 8 \times 8 \mathrm{~mm}^{3}$ sample assembly built from four $4 \times 4 \times 8 \mathrm{~mm}^{3}$ blocks.

$\alpha$-phase
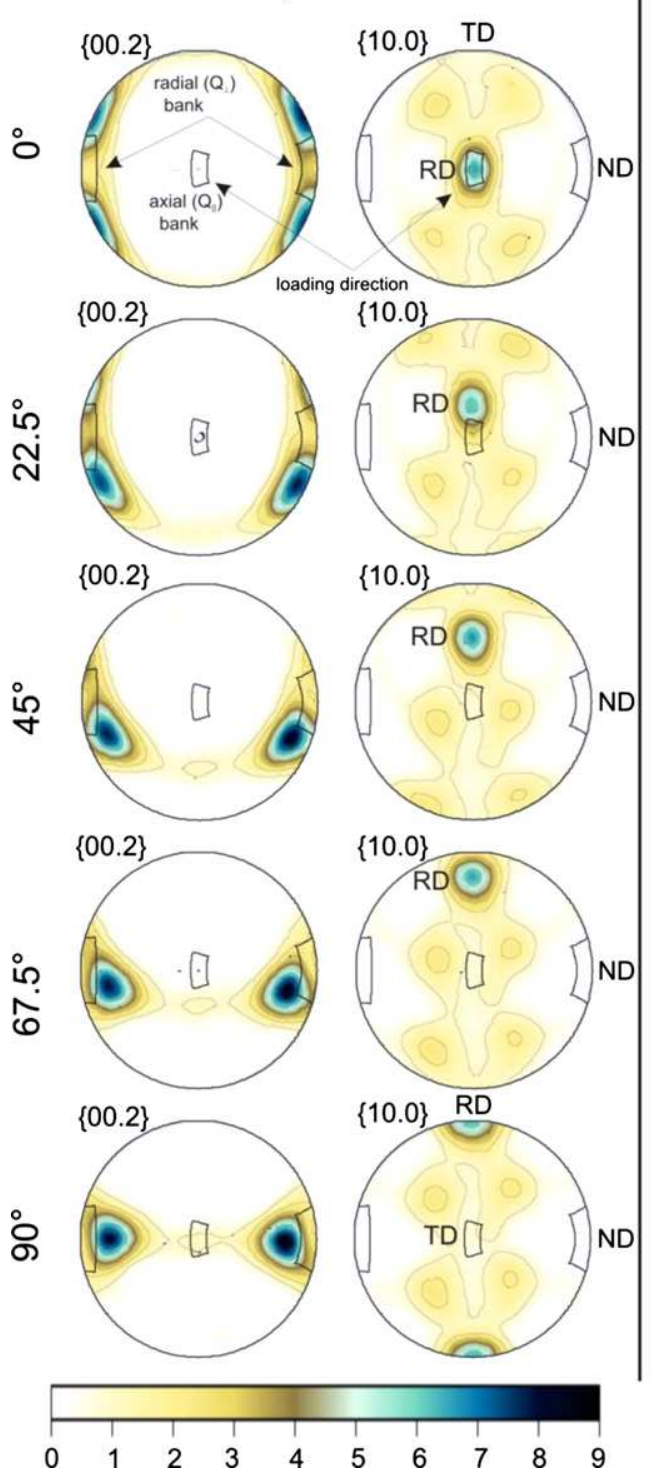

$\beta$-phase
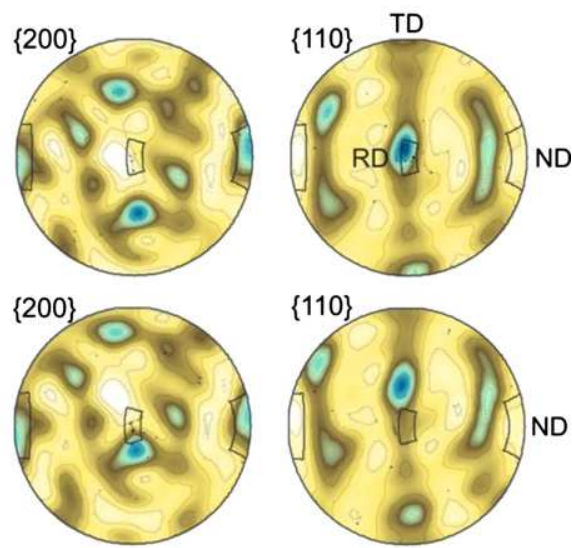

$\{200\}$
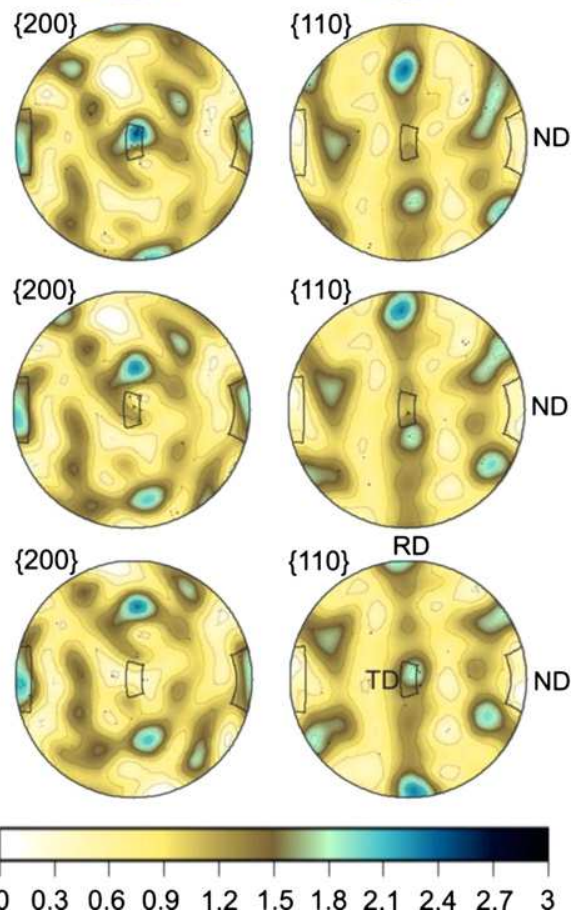

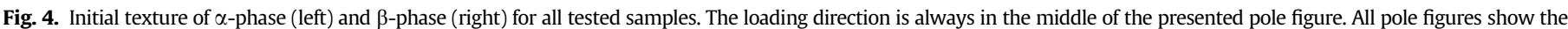

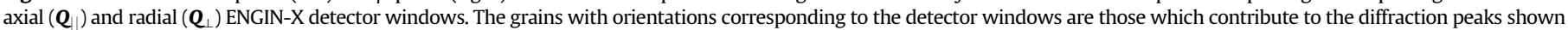
in Fig. 5. 


\subsubsection{Microstructure}

The optical and transmission electron microscopy (TEM) analysis (micrographs shown in Fig. 2a) have revealed that the $\alpha$ phase grains ( $\alpha \mathrm{Zr}$, bright) of average length of $2-3 \mu \mathrm{m}$ are aligned with the rolling direction (RD) and separated by near-continuous strips of $\beta$-phase grains ( $\beta Z$ r, dark) along the $\alpha$-phase grain boundaries. The $\alpha$-phase grains seem to be narrower $(<1 \mu \mathrm{m}$, Fig. 2a) in the normal direction (ND) and wider ( $<2 \mu \mathrm{m}$, Fig. 2b) in the transverse direction (TD). It has been further found that in some $\beta$-phase grains a nano-lamellar $\alpha \mathrm{Zr}$ is present in the form of a so-called "basket weave" structure as can be seen in Fig. 2d. Observed $\alpha$-phase needles are just a few nanometres in size and separated by even finer retained $\beta$-phase.

\subsubsection{Texture}

The initial (as-cold-rolled) texture of the studied material shown in Fig. 4 was measured using the time-of-flight (TOF) neutron powder diffractometer (HIgh Pressure Preferred Orientation, HIPPO) at Los Alamos National Laboratories in the USA [11,12]. The texture analysis was done using a full pattern Rietveld approach with X orientations/Y histograms per sample, using the MAUD program and methods described in Wenk et al. [13]. As seen in Fig. 4 , the $\alpha$-phase crystallites are preferentially oriented with the $\{00.2\}$ plane-normals $\pm 27^{\circ}$ away from the normal direction (ND) towards the transverse direction (TD) and with the $\{10.0\}$ plane-normals parallel to the rolling direction (RD). In other words, the $\alpha$-phase crystallites are oriented with their crystallographic $\langle c\rangle$ direction between the ND and TD, and with their crystallographic $\langle a\rangle$ direction towards the RD. The $\beta$-phase crystallites show the typical rolling-like texture of $b c c$ alloys with partial fibres [10]: i.e., the $\{110\}$ plane-normals parallel to the $\mathrm{RD}$ and $\{200\}$ plane-normals parallel to the ND. In comparison to the hotrolled alloys studied by Cai et al. [10] the present cold-roll sheet has a considerably sharper and stronger texture, for example the maximum

Table 1

EPSC-calculated single-phase Young's modulus for $\alpha$-phase and $\beta$-phase, and calculated resolved fractions of basal $\left(f_{\langle 00.2\rangle}\right)$, and prism $\left(f_{\langle 10.0\rangle}\right)$ plane-normals for $\alpha$-phase oriented (diffracting) in the loading direction (i.e. axial ( $\boldsymbol{Q}_{\|}$) direction) and Poisson's direction (radial $\left(\boldsymbol{Q}_{\llcorner}\right)$direction) in all tested samples.

\begin{tabular}{|c|c|c|c|c|c|c|}
\hline \multirow[t]{2}{*}{ Sample } & \multicolumn{2}{|c|}{$\boldsymbol{f}_{\langle\mathbf{0 . 0 2}\rangle}$} & \multicolumn{2}{|c|}{$\boldsymbol{f}_{\langle\mathbf{1 0 . 0}\rangle}$} & \multicolumn{2}{|c|}{ Single-phase Young's modulus } \\
\hline & $\boldsymbol{Q}$ & $\boldsymbol{Q}_{\perp}$ & $\boldsymbol{Q}$ & $\boldsymbol{Q}_{\perp}$ & $E[\alpha](\mathrm{GPa})$ & $E[\beta](\mathbf{G P a})$ \\
\hline $\mathbf{0}^{\circ}$ (RD) & 0.05 & 0.69 & 0.46 & 0.16 & 97.52 & 65.24 \\
\hline 22.5 from RD & 0.08 & 0.69 & 0.43 & 0.16 & 96.35 & 62.59 \\
\hline $45^{\circ}$ from RD & 0.15 & 0.69 & 0.40 & 0.16 & 94.58 & 60.95 \\
\hline $67.5^{\circ}$ from RD & 0.22 & 0.69 & 0.36 & 0.16 & 94.35 & 63.17 \\
\hline 90 (TD) & 0.26 & 0.69 & 0.34 & 0.16 & 94.74 & 65.09 \\
\hline
\end{tabular}

a

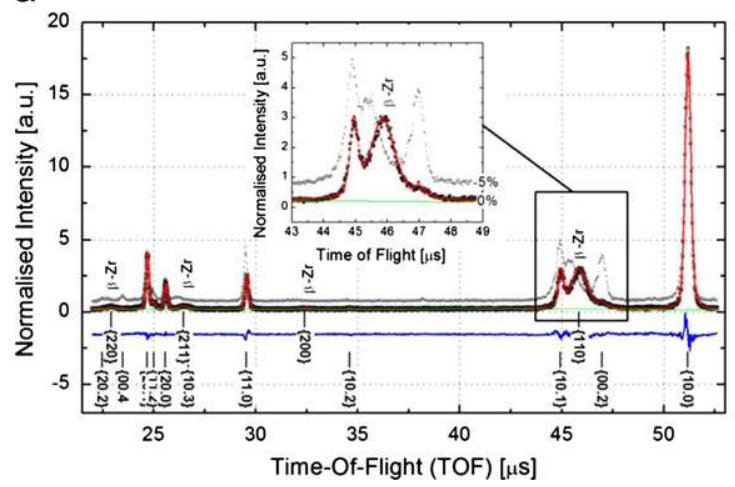

reported by Cai in Ref. [10] is 3.0 multiples of random distribution (MRD) in the $\{00.2\}$, while here it is $9.0 \mathrm{MRD}$.

As the specimen orientation changes from the RD towards the $\mathrm{TD}$, the texture gradually rotates accordingly. Note that the loading direction in Fig. 4 is always in the centre of the presented pole figure. One can see that as the loading axis rotates from the RD to the TD, a small fraction of the $\{00.2\}$ grains come into the loading direction. On the other hand, the $\{10.0\}$ grains rotate away from the loading direction. The resolved fractions of basal $\left(f_{\langle 00.2\rangle}\right)$ and prism $\left(f_{\langle 10.0\rangle}\right)$ plane-normals [14] in the loading direction for samples cut at different angle in respect to the rolling and transverse directions are summarised in Table 1.

\subsection{In situ neutron diffraction}

\subsubsection{Instrument}

The in situ neutron diffraction experiments reported here were carried out on ENGIN-X [15] at the ISIS spallation neutron source at the Rutherford-Appleton Laboratory in the UK. The diffractometer operates in time-of-flight (TOF) mode, using neutron pulses with a range of energies which travel a distance of $50 \mathrm{~m}$ towards the sample before being elastically diffracted, so that the TOF of a given neutron is proportional to its wavelength. The instrument is running at $25 \mathrm{~Hz}$ to give a window in TOF between 20,000 and $52,000 \mu$ s and in lattice spacing between 1.2 and $2.9 \AA$. ENGIN-X is equipped with an Instron loading frame $( \pm 100 \mathrm{kN})$ mounted on a positioning table in such a way that its loading axis is oriented horizontally at $45^{\circ}$ to the incident neutron beam (see Fig. 3a). As it can be further seen in Fig. 3a two detector banks placed on either side of the loading frame allow simultaneous collection of the TOF diffraction patterns (example shown in Fig. 5) with scattering vectors $(\boldsymbol{Q})$ aligned axially $\left(\boldsymbol{Q}_{\|}\right)$and radially $\left(\boldsymbol{Q}_{\perp}\right)$ to the loading axis [16], hence axial $\left(Q_{\|}\right)$and radial $\left(\boldsymbol{Q}_{\perp}\right)$ detector banks. Due to the adopted diffraction geometry, each $\{$ hk.l\} reflection in the diffraction pattern is inherently associated with a distinct family of polycrystalline grains having their $\{$ hk.l\} plane-normals oriented in the direction of the scattering vector. Hence, in the axial $\left(\boldsymbol{Q}_{\mid}\right)$ detector bank are detected grains with the $\{\text { hk.l }\}_{\|}$plane-normals oriented along the loading axis, while in the radial detector bank are detected grains with $\{$ hk.l\} $\mid$ plane-normals oriented perpendicular to the loading axis. The detectors coverage in the $\boldsymbol{Q}$ direction is half of the detectors' angular spread in the horizontal plane (i.e., $\pm 8^{\circ}$ ) and nearly equal to the angular coverage out of this plane (i.e., $\pm 18^{\circ}$ ) [16], see detector windows shown in Fig. 4 .

\subsubsection{In situ tests}

The in situ compression tests were conducted in an incremental mode in combined stress-strain control mode. This means

\section{b}

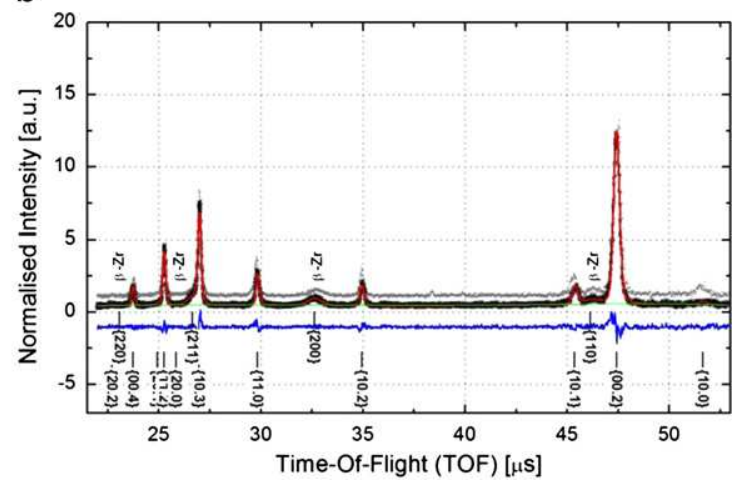

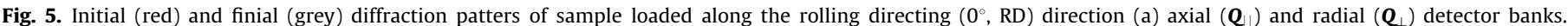
(For interpretation of the references to color in this figure legend, the reader is referred to the web version of this article.) 
that the applied loading was temporally interrupted to allow the neutron diffraction data acquisition at constant level of either applied stress or strain. Each neutron data acquisition step required an interruption of the loading for approximately $20 \mathrm{~min}$ in order to obtain satisfactory counting statistics in the diffraction patterns. It is usual to see some limited creep flow in the stress control mode, i.e., where the applied stress is held at a constant level during the neutron diffraction data acquisition, and a stress relaxation in the strain control mode, i.e., where the applied strain was held constant during the neutron diffraction data acquisition. This type of inaccuracy is unavoidable in the in situ neutron diffraction experiment due to the relatively low neutron flux and necessary stops for neutron diffraction data acquisition.

During in situ loading samples were oriented with respect to the loading axis and two detector banks as follows: (1) loading direction and thus grains diffracting into the axial $\left(\boldsymbol{Q}_{1}\right)$ detector bank were changing from the rolling direction (RD) to the transverse direction (TD) in accordance to the orientation that the sample was cut (centre of the pole figure, see Fig. 4); (2) the first Poisson direction was changing from the TD to RD but this direction was not registered in either of two detector banks; (3) the second Poisson direction was always the ND, and the sample was oriented in such a way that the grains oriented in the ND could diffract into the radial $\left(\mathbf{Q}_{\perp}\right)$ detector bank, see Figs. 3b and 4.

\subsubsection{Diffraction data analysis}

The analysis of the neutron diffraction data collected in situ during compression tests consists of monitoring relative changes in: (i) the $h k . l$ integral intensities $\left(\mathrm{I}_{h k . l}\right)$; (ii) $h k . l$ diffraction peak positions $\left(\mathrm{d}_{h k . l}\right.$ - lattice spacing) [17]; and (iii) phase lattice parameters $\left(a_{p h}, c_{p h}\right)$ as a function of the applied load. A single-peak fitting routine (Rawplot) [18,19] was used for fitting the single-peak parameters (i.e., peak position and integral intensity), whereas multi-peak LeBail analysis [18,19] was performed on the full diffraction patterns (see examples of recorded full diffraction patterns in Fig. 5) in order to monitor the relative change in lattice parameters of both present phases.

It has been previously shown that the changes in the diffraction intensities during straining can be associated with (i) the phase transformation or/and (ii) grain rotation due to ongoing dislocation slip (e.g. in Ref. [20]) or twinning (e.g. in Refs. [21,22]). On the other hand, a relative shift in the $h k . l$ peak position from its initial stressfree position reflects the average elastic strain within the particular $\{h k . l\}$ grain family. This is simply calculated as follows: $\varepsilon_{h k . l}=\left(d_{h k . l}-d_{0, h k l}\right) / \mathrm{d}_{0, h k . l}[17]$, where $d_{0, h k . l}$ is the initial stress-free $h k . l$ lattice spacing recording prior to loading. Similarly, a relative shift in the $a$-lattice parameter from the initial stress-free $a$-lattice parameter reflects the average elastic phase strain within the particular cubic phase, i.e., for bcc $\beta$-phase: $\varepsilon_{a}(\beta)=\left(a_{\beta}-a_{0, \beta}\right) / a_{0, \beta}$. This is, however, more complicated in the hexagonal $\alpha$-phase, because a relative change in the $a$-lattice parameters reflects only the average elastic phase strain response of the diffracting crystallites along their $\langle a\rangle$ crystallographic direction, $\varepsilon_{a}(\alpha)=\left(a_{\alpha}-a_{0, \alpha}\right) /$ $a_{0, \alpha}$, and similarly a relative change in the $c$-lattice parameter reflects only the average elastic phase stain response along the $<$ $c)$ direction of the diffracting crystallites, $\varepsilon_{c}(\alpha)=\left(c_{\alpha}-c_{0, \alpha}\right) / c_{0, \alpha}$. The overall average response of the hexagonal $\alpha$-phase, $\varepsilon_{c, a}(\alpha)$, can be calculated from the average elastic phase strains in the $\langle a\rangle$ and \langle $c\rangle$ crystallographic directions using the texture-weighted factor as follows [14]: $\varepsilon_{c, a}(\alpha)=f_{\langle 00.2\rangle} . \varepsilon_{c}(\alpha)+\left(1-f_{\langle 00.2\rangle}\right) . \varepsilon_{a}(\alpha)$, where $f_{\langle 00.2\rangle}$ is the resolved fraction of basal plane-normals in the direction of interest (i.e., texture-weighted factor, see Table 1). a

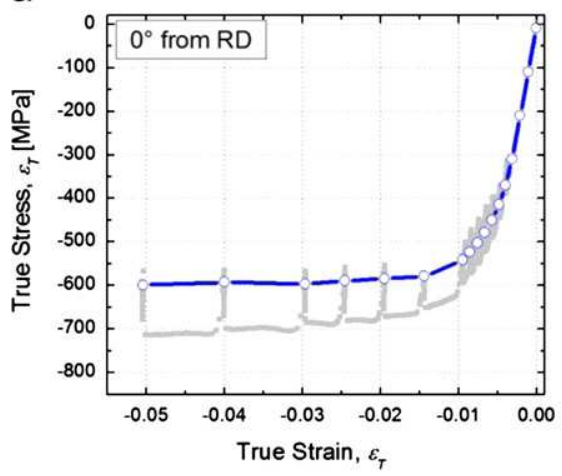

d

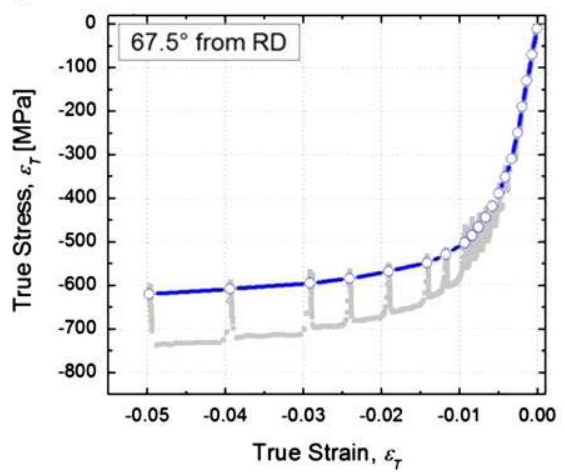

b

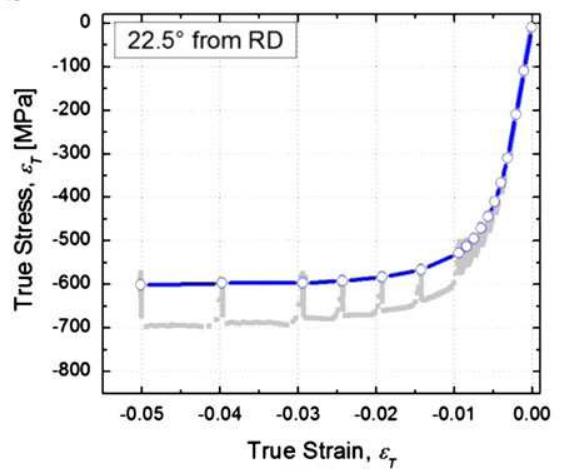

e

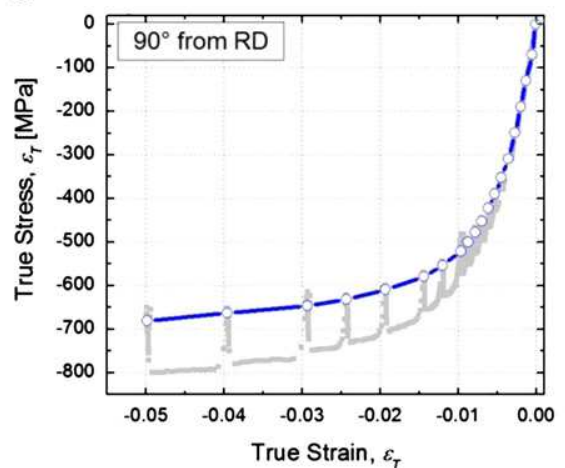

C

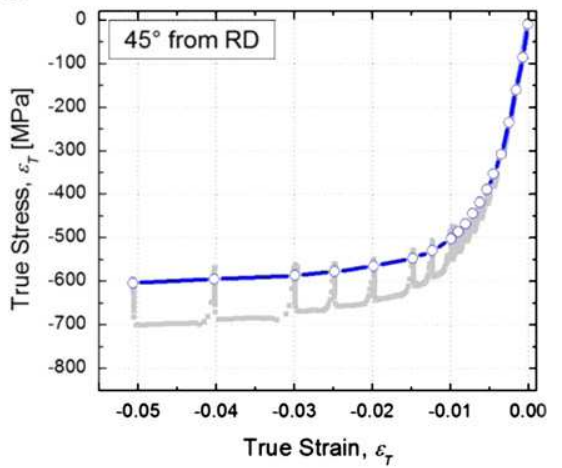

$f$

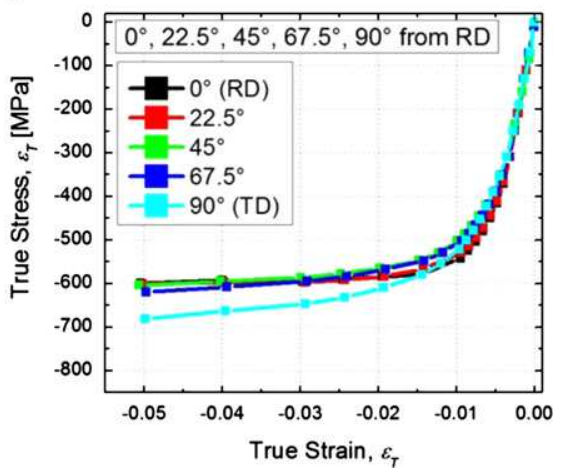

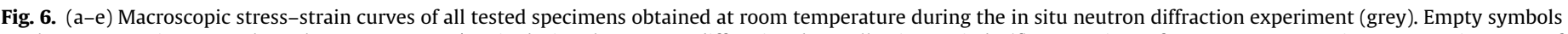

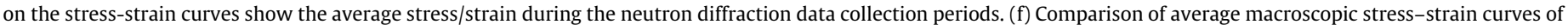
all tested specimens. 


\section{Results and discussion}

\subsection{Macroscopic behaviour}

The in situ recorded macroscopic stress-strain responses of the studied cold-rolled $\mathrm{Zr}-2.5 \% \mathrm{Nb}$ sheet, in compression along the axis: $0^{\circ}, 22.5^{\circ}, 45^{\circ}, 67.5^{\circ}$ and $90^{\circ}$ from the rolling direction (RD) are shown in Fig. 6 (grey). Notice that the stress-strain curves show stress-relaxation of about $100 \mathrm{MPa}$ at strains where the applied strain was temporarily held constant (i.e., in strain control mode, > $300 \mathrm{MPa}$, i.e., plastic region) for approximately $20 \mathrm{~min}$ in order to allow the neutron diffraction data acquisition at the constant level of applied strain. In the stress-control mode, $<300 \mathrm{MPa}$, i.e., elastic region, stress-strain curves show very small amount of creep flow. As mentioned above this type of inaccuracy is unavoidable in the in situ neutron diffraction mechanical loading experiments due to the time required to obtain reasonable counting statistics in neutron diffraction patterns. The open symbols connected by a blue line in Fig. 6 show the average applied stress/strain at which the neutron diffraction pattern has been collected during the in situ loading. Overall there is only a slight difference in the mechanical properties between the samples tested at different angles. The following can be concluded from the present macroscopic stress-strain response: (i) the macroscopic Young's

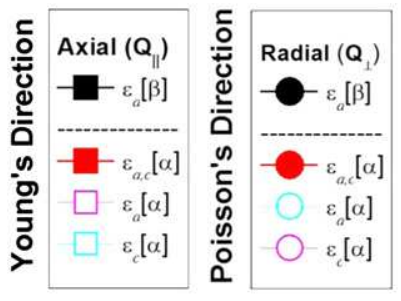

b

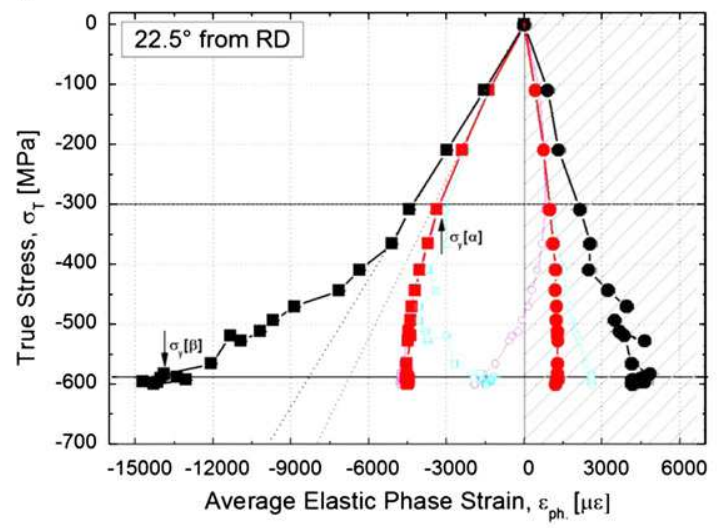

d

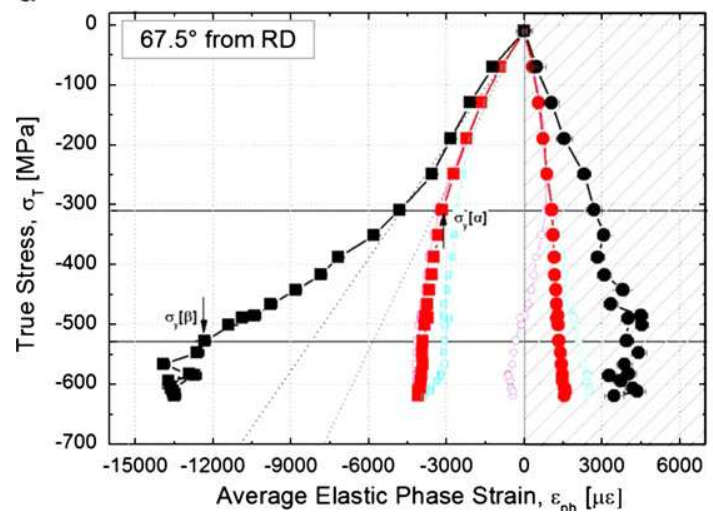

a

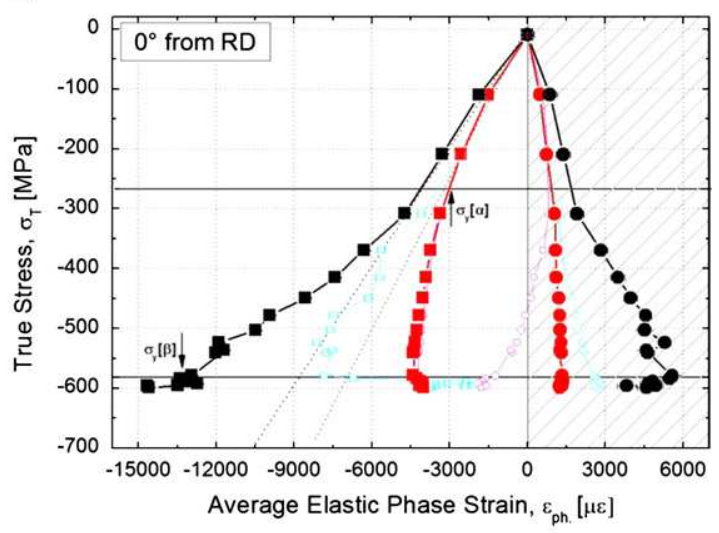

C

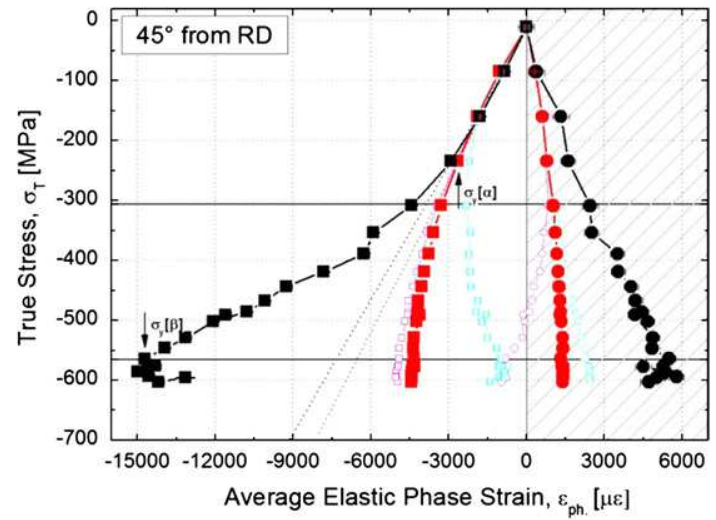

e

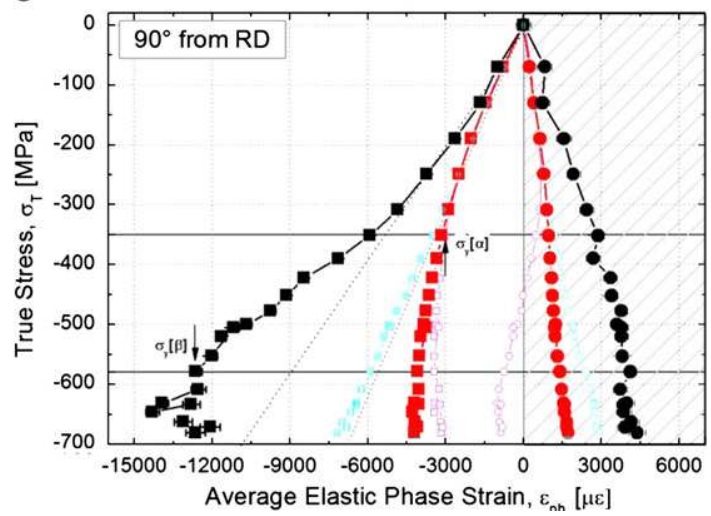

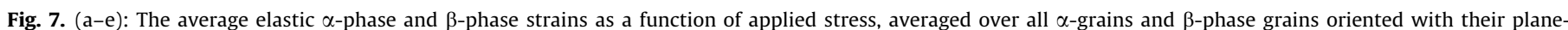

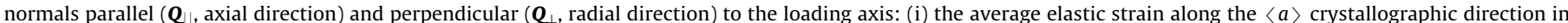

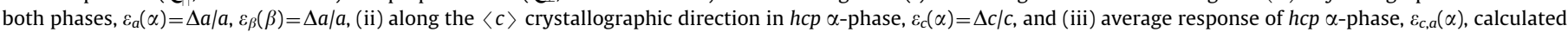

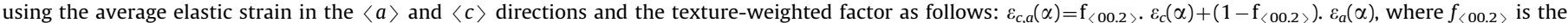
resolved fraction of basal plane-normals in the direction of interest, i.e. axial or radial, see Table 1. 
modulus differs between the samples only within the experimental error, this agrees with Elasto-Plastic Self-Consistent (EPSC) [23,24] modelling results shown in Table 1 (note, that the macroscopic Young's modulus of a multiphase material can be estimated by the rule of mixture); (ii) all the samples have a smooth elasto-plastic transition with only slightly varying yield strength; and (iii) the macroscopic strain-hardening slightly increases from the rolling direction (RD) to transverse direction (TD).

\subsection{Diffraction results}

\subsubsection{Evolution of average phase strains}

Fig. 7 shows the development of the average elastic phase strains along the $\langle a\rangle$ crystallographic direction in both existing phases, $\varepsilon_{a}(\alpha), \varepsilon_{a}(\beta)$ and along the $\langle c\rangle$ crystallographic direction in the hexagonal $\alpha$-phase, $\varepsilon_{c}(\alpha)$. The texture-weighted average $\alpha$-phase strains, $\varepsilon_{a, c}(\alpha),[14]$ are also shown in order to see overall average behaviour of the $\alpha$-phase. From Fig. 7 it is clear that the $\beta$-phase is the elastically more compliant phase with a lower Young's modulus than the $\alpha$-phase, this is in agreement with earlier observations $[9,25,26]$ and EPSC modelling predictions shown in Table 1. Note that the EPSC model [24] calculates the single-phase Young's modulus based on the single-crystal elastic constants [27] and measured initial texture. The following can be concluded from Table 1: (i) the Young's modulus of the $\alpha$-phase decreases from $0^{\circ}$ to $67.5^{\circ}$ as the number of elastically mediumhard $\{10.0\}$ grains decreases (see the texture measurements in Fig. 4), while in the sample $90^{\circ}$ (TD) the Young's modulus of the $\alpha$-phase slightly increases because of a higher number of elastically hard $\{00.2\}$ grains in accordance with the measured texture, and (ii) the Young's modulus of the $\beta$-phase is strongly dependent on the increase of the elastically softest $\{200\}$ grains (max. in sample $45^{\circ}$, Fig. 4) and the decrease of the elastically hardest $\{110\}$ grains (max. in sample $0^{\circ}(\mathrm{RD})$, and $90^{\circ}(\mathrm{TD})$, see Fig. 4). These single-phase elastic constants differ from those measured in the diffraction experiment because of the constraint imposed by one phase on another in the phase-to-phase interactions within a multiphase material. This phase-to-phase interaction modifies the elastic constant from the true constraint-free (single phase) Young's modulus upon straining. Nevertheless, it is clear, in agreement with the EPSC calculations, that the $\beta$-phase is the more compliant phase in the elastic region. The situation, however, changes dramatically at the onset of plasticity in the $\alpha$-phase. Note, that due to the higher portion of the applied load which is borne by the $\alpha$-phase in this dual-phase alloy, it yields at a lower applied stress than it would as a single-phase alloy. From
Fig. 7 it can be seen that the $\alpha$-phase starts to yield, i.e., shed the load in favour of the $\beta$-phase at an applied stress of about $-280 \mathrm{MPa}$ in sample cut along the rolling direction $\left(0^{\circ}, \mathrm{RD}\right)$ and about $-350 \mathrm{MPa}$ in sample cut along the transverse direction $\left(90^{\circ}, \mathrm{TD}\right)$. This is manifested by an increase in the $\beta$-phase lattice strain and a strain relief in the $\alpha$-phase lattice strain in both measured directions. Hence, it is clear that the $\beta$-phase acts as a reinforcing phase and the applied load is gradually transferred from the plastically deformed - elastically harder $\alpha$-phase matrix towards the plastically harder - elastically softer $\beta$-phase grains. The yield stress of the $\alpha$-phase can be in the first approximation estimated using the uniaxial Hooke's law $(\sigma=\mathrm{E} . \varepsilon)$, taking the average single-phase elastic modulus shown in Table 1 and measured average phase strain at the onset of yielding in the $\alpha$-phase. (The onset of yielding is denoted by the point where the true stress - elastic strain curve for the phase deviates downwards from the elastic straight line.) Thus, it can be seen that the yield strength of the $\alpha$-phase continuously increases from $-290 \mathrm{MPa}$ in sample cut along the rolling direction $\left(0^{\circ}, \mathrm{RD}\right)$ to $-315 \mathrm{MPa}$ in sample cut along the transverse direction (90 ${ }^{\circ}$, TD).

The $\beta$-phase commences to yield at an applied stress of roughly $-580 \mathrm{MPa}$ (see the second inflection point, i.e., when the average $\beta$-phase, $\sigma_{\mathrm{y}}(\beta)$, lattice strain discontinues increasing with the applied stress. Note, also that the average response of the $\beta$-phase is much more dramatic than the $\alpha$-phase because of its relatively small volume fraction and the requirement to maintain an overall stress balance. Taking into account the single-phase elastic constants in Table 1, it can be roughly estimated that the yield strength of the $\beta$-phase is in the range from -750 to $-900 \mathrm{MPa}$. It was suggested in Ref. [10] that the unexpectedly high strength of the $\beta$-phase might be due to (i) the segregation of alloying elements and (ii) its fine grain size. Fig. 2e presents the energy-dispersive X-ray spectroscopy (EDS) analysis along the measuring line confirming segregation of $\mathrm{Nb}$, and $\mathrm{Fe}$ in $\beta$-phase grain. Later observations on a large grain size $\beta$-phase alloy [14] suggested that this alloying contribution is the major hardening effect. Similar chemical strengthening effects are observed in TRIP steels, where the finely-dispersed carbon-stabilized (C-rich) retained austenite is plastically harder than the typically harder ferrite-banite matrix [28]. However, although the strength of the $\beta$-phase is more-or-less consistent between the samples, one can see in Fig. $7 \mathrm{c}$ that the $\beta$-phase starts to yield in sample $45^{\circ}$ with the axial internal strain of nearly $15000 \mu \varepsilon$ (clearly higher than in the other samples) suggesting nearly $-900 \mathrm{MPa}$ yield strength. This shows the effect of the strong texture also found in the $\beta$ phase and it agrees with respect to the high volume fraction of
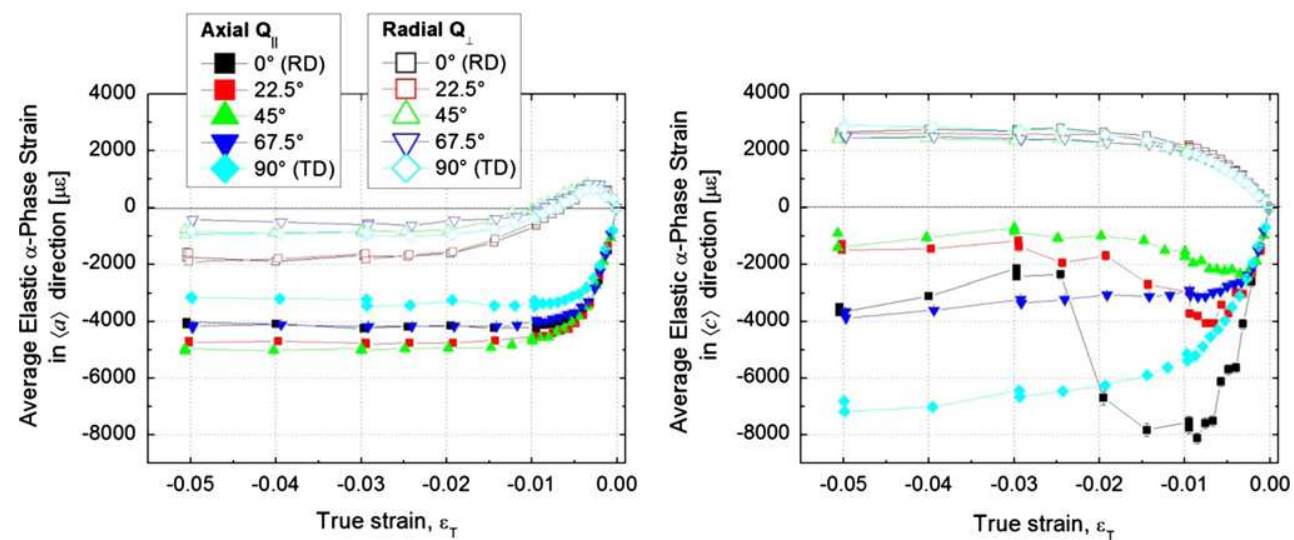

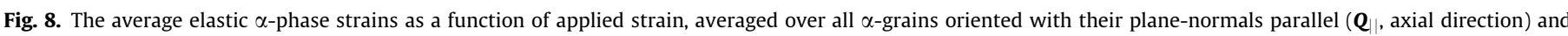

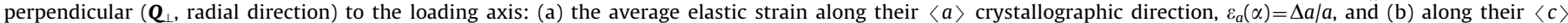
crystallographic direction, $\varepsilon_{c}(\alpha)=\Delta c / c$. 
the plastically hardest $\{200\}$ grains [10] in this sample orientation, see the texture measurements in Fig. 4. The estimated yield stress of the $\beta$-phase in [10] was $\sim 560 \mathrm{MPa}$; presumably the higher yield stress observed here arises due to the very fine grain size, ranging in size from a few nanometres between the needles of $\alpha$-phase in the "basket weave" structure (Fig. $2 d$ ) to a few tens/ hundreds of nanometres separating the $\alpha$-phase grains. Additionally, constraint associated with the highly textured $\alpha$-phase might play a role in higher yield strength of the $\beta$-phase.

It is, also, useful to study the evolution of the average $\alpha$-phase strain along the $\langle a\rangle$ and $\langle c\rangle$ crystallographic directions individually. One needs to be, however, careful when analysing the Rietveld-averaged strains in $h c p$ metals, because of the texture-weighted directional averaging over many \{hk.l\} grain families [29]. The average $\langle c\rangle$ direction in Rietveld refinement is defined by all \{hk.l\} grain families for which $l \neq 0$, and similarly the response in the $\langle a\rangle$ crystallographic direction is Rietveldaveraged over all the hk.l grain families for which $h \neq 0$. For better comparison of the average strain along the $\langle a\rangle$ and $\langle c\rangle$ directions in the $\alpha$-phase, Fig. 8 presents its development as a function of true strain rather than true stress. It can be seen in Fig. $8 \mathrm{~b}$ that there is an elastic strain relief along the $\langle c\rangle$ direction of $\alpha$-phase grains for samples loaded $0^{\circ}, 22.5^{\circ}$, and $45^{\circ}$ from rolling direction (RD). This implies the activation of $a\langle c\rangle$ or/and $\langle c+a\rangle$ deformation mechanism. One can, however, clearly see in Fig. 8 that the magnitude of the lattice strain relief in $\langle c\rangle$ direction significantly decreases with the increasing loading angle from the rolling direction (RD) towards the transverse direction (TD). This suggests the change in the activity of $a\langle c\rangle$ direction operating deformation mode between the tested samples. In contrast, the $\langle c\rangle$ direction does not seem to show any elastic strain relief in samples loaded $67.4^{\circ}$ and $90^{\circ}$ (TD) from the rolling direction (RD), suggesting difficulty in plasticity along the $\langle c\rangle$ axis in these samples. As expected the $\alpha$-phase grains are, on average, in tension along their $\langle c\rangle$ axis in the Poisson's direction (ND) in all tested samples. However, it is interesting to notice that the same grains are, on average, in compression along their $\langle a\rangle$ axis in the Poisson's direction (see Fig. 8a). see. This must be due to the strong initial texture (notice the low resolved fraction of the prism plane-normals in the Poisson direction Table 1) and averaging in the Rielveld refinement and it is thus more difficult to understand without micro-mechanical modelling. Nevertheless, one might see somewhat higher compression stresses along the $\langle a\rangle$ crystallographic direction in the Poisson's direction in

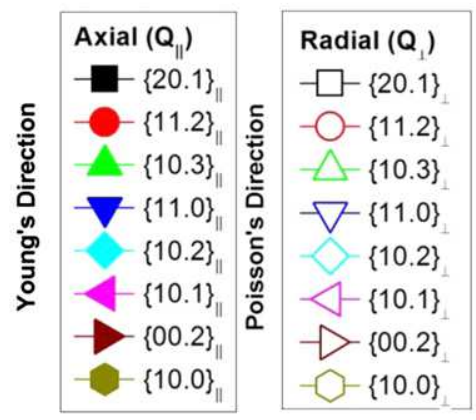

a

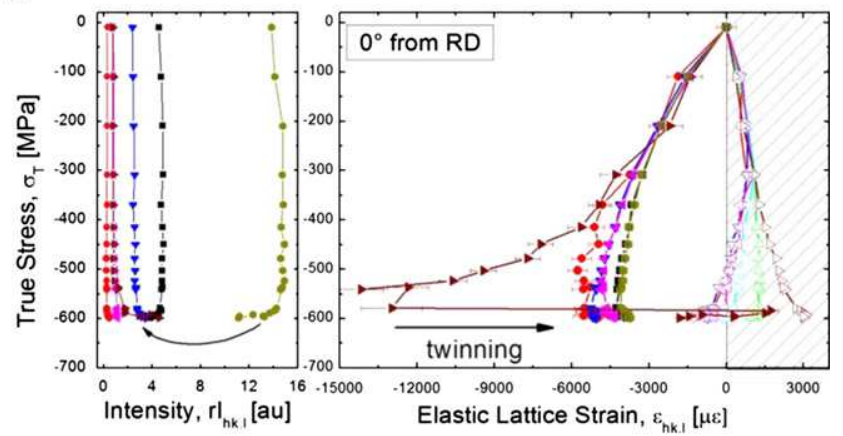

b
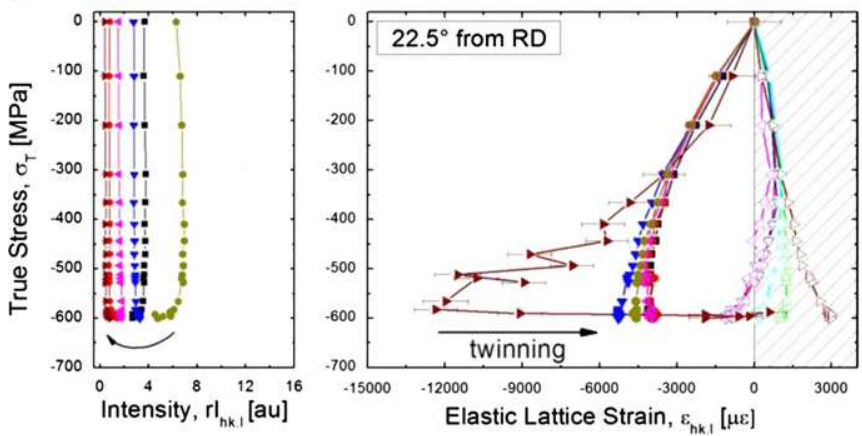

C

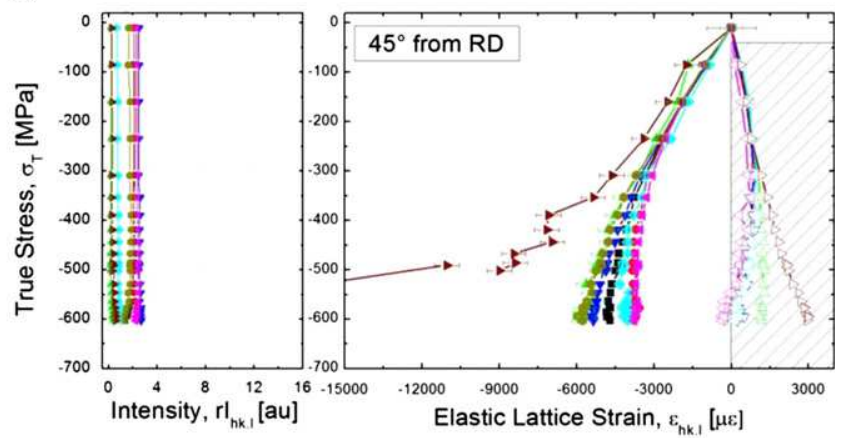

d
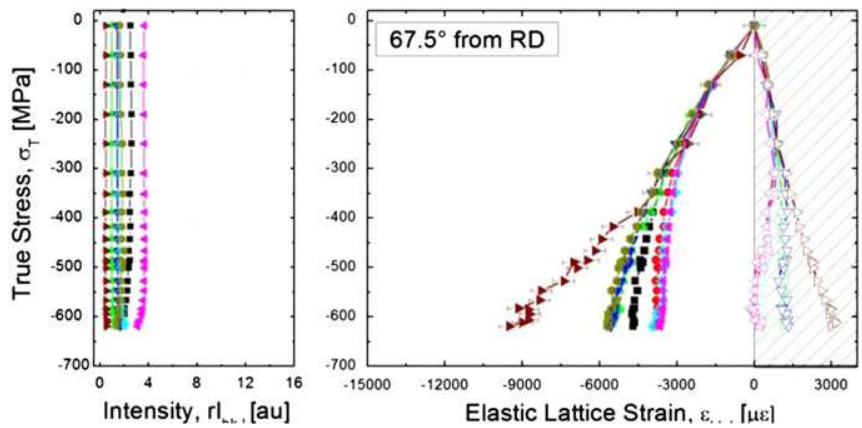

e

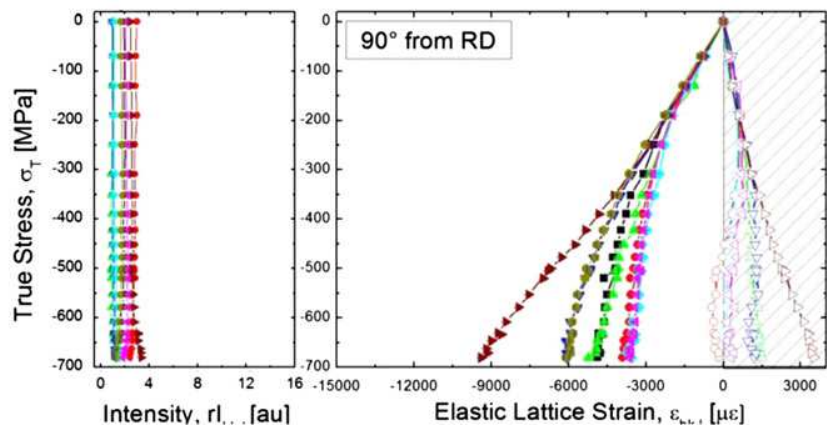

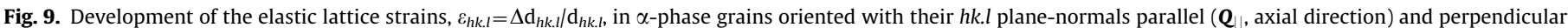
$\left(\boldsymbol{Q}_{\perp}\right.$, radial direction) to the loading axis and the evolution of reduced integral intensities, $r I_{h k . l}$, of diffraction peak recorded in the axial $\left(\boldsymbol{Q}_{\|}\right)$detector bank. 
samples loaded along the axis $0^{\circ}$, and $22.5^{\circ}$ from rolling direction (RD) - i.e., the same samples which show a noticeable lattice strain relief along the $\langle c\rangle$ axis in the loading direction.

\subsubsection{Evolution of lattice strains and diffraction intensities}

The development of the $h k . l$ lattice strains in $h k . l \alpha$-phase grain families, $\varepsilon_{h k . l}(\alpha)$, in both measured directions and evolution of the reduced integrated intensities, $r I_{h k . l}(\alpha)$ in the loading direction are shown in Fig. 9. (Note, that the measured integral intensities are reduced by: (i) $\left(d_{h k . l}\right)^{4}$ (lattice spacing), (ii) $\left|F_{h k . l}\right|^{2}$ (structure factor), and (iii) $m_{h k . l}$ (multiplicity) and are hence proportional to the volume occupied by particular $h k . l$ grains, oriented such that they fulfil the diffraction condition in the detector bank [28].) It is clear that in all tested samples all studied $h k . l$ grain families have a very similar response in the elastic region which agrees well with the low elastic anisotropy of the $\alpha$-phase. The most striking observation is a dramatic strain relief in the $\{00.2\}_{||}$grain families (i.e., grains compressed parallel to their $\langle c\rangle$ axis) at the applied stress of about $-600 \mathrm{MPa}$ in samples loaded along $0^{\circ}$, and $22.5^{\circ}$ from rolling direction (RD) (Fig. 9a,b). As further seen in Fig. 9a,b this sudden stress relief in the $\{00.2\}_{\|}$grains is accompanied by a sudden increase in the $\{00.2\}_{\|}$diffraction peak intensity and a concurrent decrease in the $\{10.0\}_{\|}$diffraction peak intensity, this reflects a change in the grain volume fraction diffracting into the axial $\left(\boldsymbol{Q}_{\mid}\right)$detector bank. It has been previously shown e.g. in Refs. $[21,22]$ that in respect to the adopted diffraction geometry, such a dramatic intensity exchange between the $\{10.0\}_{\|}$and $\{00.2\}_{\|}$diffraction reflections and the lattice strain relief can be associated with the operation of the $\{1-1.2\}\langle 1-1 .-1\rangle$ "tensile" twinning mode which reorientates the parent $\{10.0\}_{\|}$crystal lattice by $\sim 86^{\circ}[30]$ to the new twin $\{00.2\}_{\|}$orientation (this can be still detected in the axial $\left(\boldsymbol{Q}_{\|}\right)$ detector bank because of the wide detector window, see Fig. 4). Strictly speaking the lattice strain relief in $\{00.2\}_{\|}$lattice strain reflects the onset of the plasticity in the $\{10.0\}_{||}$grains along their $\langle c\rangle$ crystallographic direction which is being accommodated by "tensile" twinning. (Note, that $\{10.0\}_{\|}$grains have the highest Schmid factor (0.5) for this twinning mode). In Fig. 9 it can be further seen that there is also a considerable decrease in the diffraction intensity of the $\{20.1\}_{\|}$reflection in samples loaded along the axis $0^{\circ}$ and $22.5^{\circ}$ from rolling direction (RD), this suggests some twinning activity also in the $\{20.1\}$ grains. (Note, that these grains also have a high Schmid factor $(0.45)$ for tensile twinning mode, but the newly formed twin grains originating from the parent $\{20.1\}_{\mid}$cannot be detected with the current diffraction geometry [16].)

It is further important to point out that the lattice strain relief in $\{00.2\}_{\|}$lattice strain associated with the onset of twinning in the $\{10.0\}_{||}$grains does mean that the initially present $\{00.2\}_{\|}$ grains commenced to yield. The observed strain relief is due to the neutron diffraction averaging which includes stressed initially present $\{00.2\}_{\|}$grains as well as relaxed newly born $\{00.2\}$ twin grains creating an average over two populations [6,31]. The evolution of the $\alpha\{10.1\}_{\|}, \beta\{110\}_{\|}$and $\alpha\{00.2\}_{\|}$diffraction peaks as a function of applied strain is also shown in Fig. 10 for samples loaded along the axis $0^{\circ}, 22.5^{\circ}$ and $45^{\circ}$ from rolling direction (RD). Hence, it becomes clear that there is a direct evidence of deformation twinning in the $\{10.0\}_{\|}$parent grains only in samples $0^{\circ}$ and $22.5^{\circ}$, i.e., in samples with high volume fraction of $\{10.0\}_{\|}$grains (see resolved fraction of prism plane-normals, Table 1, and Fig. 4). This, however, does not mean that there is not some twinning activation in samples loaded along the axis closer to transverse direction (TD), which remains undetected due to the adopted diffraction geometry. The slight strain relief along the $\langle c\rangle$ direction in sample cut $45^{\circ}$ from rolling direction (RD) as shown in Fig. 8b and discussed above suggests that there is some activity along the $\langle c\rangle$ axis; however the newly formed twins might have ended up outside of the detector coverage or their volume fraction may be below the instrumental resolution. Nevertheless, it stands to reason that, as the volume fraction of the favourably twin-oriented $\{10.0\}$ grains decreases from the rolling direction (RD) to transverse direction (TD) (see Fig. 4) the twinning becomes less favourable.

Cai et al. $[9,10]$ did not see any twinning activity in the $\alpha$-phase of their $\mathrm{Zr}-2.5 \% \mathrm{Nb}$ alloy (either by neutron diffraction or TEM) despite the coarser grains, this is presumably due to the weak texture of their alloy (see Fig. 2 in Ref. [10]), which resulted in a low constraint to enforce twinning. The current results thus provide a first demonstration of twinning in a fine-grained $\mathrm{Zr}-2.5 \% \mathrm{Nb}$ alloy at room temperature. While the neutron diffraction suggests the activation of $\{1-1.2\}\langle 1-1 .-1\rangle$ "tensile" twinning mode in samples loaded $0^{\circ}$ and $22.5^{\circ}$ from the rolling direction (RD), a TEM analysis was performed to confirm the presence of these twins, and further to a

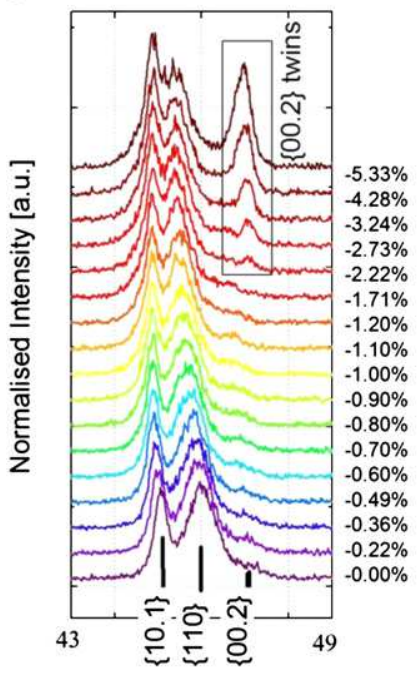

b

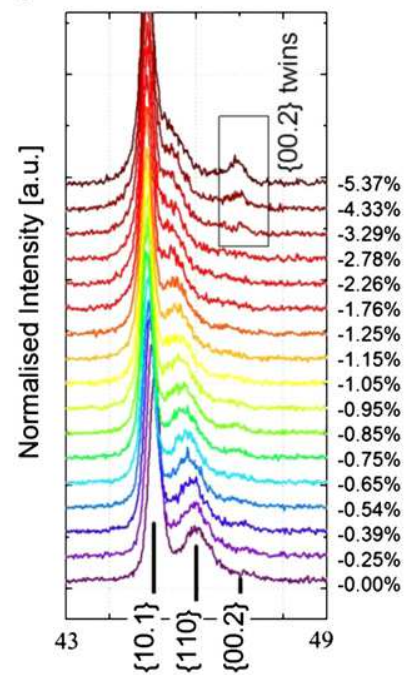

C

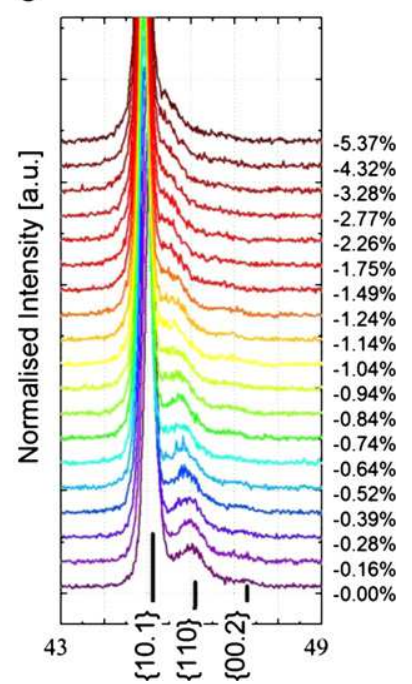

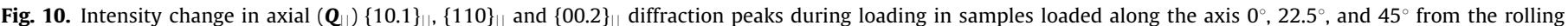
direction (RD). 
a

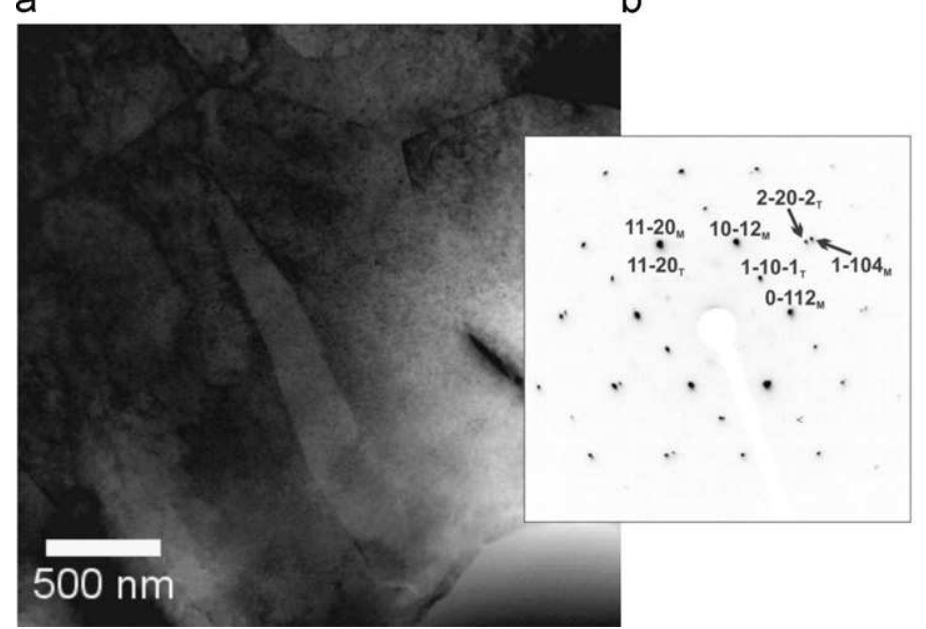

C

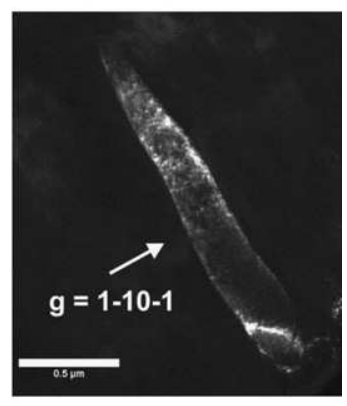

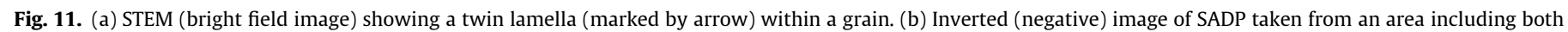
the matrix grain and the twin-zone axes: $[-22.1]_{\mathrm{M}}$ and $[1-1.2]_{\mathrm{T}}$. (c) STEM (dark-field image) of the twin using the $\mathbf{g}=1-1 .-1$ beam.

search for possible twins in remaining samples, particularly in the sample loaded $45^{\circ}$ from the rolling direction (RD) which did show strain relaxation along the $\langle c\rangle$ axis (Fig. 8b), and last but not least to determine if other type of twins are present in any of the samples.

\subsection{TEM results}

The presence of "tensile" twins in the cold-rolled sample was verified using Transmission Electron Microscopy (TEM). Twins were easy to find in samples loaded $0^{\circ}$ and $22.5^{\circ}$ from the rolling direction (RD), however, it was not possible even on multiple samples to find any twins in samples loaded closer to the transverse direction (TD), not even in the sample loaded $45^{\circ}$ from the rolling direction (RD). This is despite the fact that neutron diffraction suggests very slight strain relaxation along the $\langle c\rangle$ axis of the crystallites. However, considering a very small probing area in TEM analysis, the presence of deformation twins cannot be excluded. The scanning TEM (STEM) bright field (BF) image in Fig. 11a (sample loaded $22.5^{\circ}$ from RD) shows a twin inside an $\alpha$ phase grain. The selected area diffraction pattern (SADP) taken from the matrix grain (M) and the twin lamella (T) together is shown in Fig. 11b. The diffraction pattern was successfully indexed as a superimposition of $[-22.1]_{\mathrm{M}}$ and $[1-1.2]_{\mathrm{T}}$ zone axis patterns, by measurement of angles and d-spacing values, and was confirmed by simulation using the EMAPS software [32]. The twin was also imaged in dark field by using the reflections ascribed to it, and in all cases the images confirmed that the reflections were indeed from the twin. An example is given for DF image taken using the $\mathbf{g}=1-1 .-1$ reflection, as shown in Fig. 11c.

It is well known that a "tensile" twin in hcp material like $\mathrm{Zr}$ can be formed by an effective rotation about [11.0] axis by $\sim 94^{\circ}$ [33]. This is equivalent to an angle of $2 \varphi=\sim 86^{\circ}$ between $\mathrm{K} 1=\{10.2\}$ and $\mathrm{K} 2=\{-10.2\}$ [34]. On closer examination of the diffraction pattern, it is seen that the matrix and the twin have a common [11.0] pole, and the $[1-104]_{\mathrm{M}}$ and $[1-1 .-1]_{\mathrm{T}}$ poles are parallel. Since the angle between these poles is $\sim 93.88^{\circ}$ in any given $\mathrm{Zr}$ crystal, it can be stated that in the present case there is a rotation equivalent to this amount about the common [11.0] pole, giving rise to a $\{1-1.2\}\langle 1-1 .-1\rangle$ "tensile" twin. No other twin types were identified by either TEM or neutron diffraction in any of the tested samples. This supports previous findings that the $\{11.1\}$ $\langle 11 .-6\rangle$ "tensile" twinning and $\{11.2\}\langle 11 .-3\rangle$ "compression" twinning modes are active only at low temperatures $(<150 \mathrm{~K})$ [35]. However, it is important to mention that the strong, as-cold-rolled, texture with respect to loading direction does not favour activation of the $\{11.2\}\langle 11 .-3\rangle$ "compression" twinning mode.

\section{Conclusions}

In situ neutron diffraction loading experiments have been carried out on a cold-rolled dual-phase $\mathrm{Zr}-2.5 \% \mathrm{Nb}$ plate material in order to study the effect of crystallographic texture on the activation of deformation twinning. The studied material has typical cold-rolled microstructure with the hexagonal closepacked $\alpha$-phase grains elongated in the rolling direction (RD) and these are separated by discontinuous islands of body-centred cubic $\beta$-phase grains. Both phases show strong as-cold-rolled texture, the $\alpha$-phase crystallites are preferably oriented with their $\{10.0\}$ plane-normals parallel to rolling direction (RD), similarly the $\beta$-phase crystallites are preferably oriented with their $\{110\}$ plane-normals parallel to the rolling direction (RD). The deformation was studied at different angles in the RD-TD plane, with the loading axis gradually moving from rolling direction (RD) towards transverse direction (TD): $0^{\circ}$ (RD), $22.5^{\circ}, 45^{\circ}, 67.5^{\circ}$ and $90^{\circ}$ (TD). In addition to in situ neutron diffraction loading a TEM analysis was performed on the deformed specimen in order to identify the present deformation twins. The following conclusions are reached from the performed analysis:

(1) The neutron diffraction results show presence of load partitioning between the present phases, so that the applied load is gradually transferred from the plastically softer $\alpha$-phase towards the plastically harder $\beta$-phase which thus acts as a reinforcing phase. The $\alpha$-phase shows the yield strength of roughly $300 \mathrm{MPa}$ in all the samples, while $\beta$-phase shows the yield strength in the range 750-900 MPa, having maximum for the sample loaded $45^{\circ}$ from the rolling direction (RD), which contains the highest portion of the grains which are oriented with their $\{200\}$ plane-normals (i.e. plastically hard orientation) in the loading direction.

(2) The neutron diffraction results provide direct evidence of $\{1-1.2\}\langle 1-1 .-1\rangle$ "tensile" twinning in the hcp $\alpha$-phase at room temperature in the sample deformed along the rolling direction (RD) and $22.5^{\circ}$ from $\mathrm{RD}$. The neutron diffraction data also suggests some twinning activity in the sample loaded $45^{\circ}$ from the rolling direction (RD) via measured relaxation of 
crystallites along their crystalographic $\langle c\rangle$ direction. This, however, does not provide direct evidence (via diffraction intensity change) of any particular twinning mode activity. In addition twins were not found using the TEM technique.

(3) The TEM analysis confirmed the presence of the $\{1-1.2\}$ $\langle 1-1 .-1\rangle$ "tensile" twins in samples loaded along the rolling direction (RD) and $22.5^{\circ}$ from RD. No another type of twins were found in these samples, suggesting the importance of the $\{11.1\}$ $\langle 11 .-6\rangle$ "tensile" twinning and $\{11.2\}\langle 11 .-3\rangle$ "compression" twinning modes only at low temperatures (also note that the $\{11.2\}\langle 11 .-3\rangle$ "compression" twinning mode is suppressed by strong texture which does not favour its activation). No twins were found in samples loaded $45^{\circ}, 67.5^{\circ}$ and $90^{\circ}$ from the rolling direction $(\mathrm{RD})$.

\section{Acknowledgement}

The authors acknowledge the support from the ISIS facility, Rutherford Appleton Laboratory in the UK (proposal no. RB920055) and help by Dr Anna Paradowska. This work has benefited from the use of the Lujan Neutron Scattering Center at LANSCE, which is funded by the Office of Basic Energy Sciences, U.S. Department of Energy. Los Alamos National Laboratory is operated by Los Alamos National Security LLC under DOE Contract No. DEAC52-06NA25396.

\section{References}

[1] C.E. Liundin, R.H. Cox, in: 1 (Ed.), 1962, pp. 9.

[2] R.A. Holt, J. Nucl. Mater. 372 (2008) 182-214.

[3] R.J. McCabe, E.K. Cerreta, A. Misra, G.C. Kaschner, C.N. Tomé, Philos. Mag. A 86 (2006).

[4] S.G. Song, G.T. Gray Iii, Acta Metall. Mater. 43 (1995) 2325-2337.

[5] S.G. Song, G.T. Gray Iii, Acta Metall. Mater. 43 (1995) 2339-2350.

[6] O. Muránsky, D.G. Carr, P. Šittner, E.C. Oliver, Int. J. Plasticity 25 (2009) 1107-1127.

[7] J.W. Christian, S. Mahajan, Prog. Mater. Sci. 39 (1995) 1-157.
[8] S.G. Song, G.T. Gray, Metall. Mater. Trans. A 26 (1995)

[9] S. Cai, M.R. Daymond, R.A. Holt, E.C. Oliver, Acta Mater. 59 (2011) 5305-5319.

[10] S. Cai, M.R. Daymond, R.A. Holt, M.A. Gharghouri, E.C. Oliver, Mater. Sci. Eng. A 501 (2009) 166-181.

[11] H.R. Wenk, L. Lutterotti, S. Vogel, Nucl. Instrum. Methods Phys. Res. Sect. A 515 (2003) 575-588.

[12] S. Matthies, J. Pehl, H.-R. Wenk, L. Lutterotti, S.C. Vogel, J. Appl. Crystallogr. 38 (2005) 462-475.

[13] H.-R. Wenk, L. Lutteroti, S.C. Vogel, Rietveld texture analysis from TOF neutron diffraction data, Power Diffr. 25 (2010).

[14] R.A. Holt, E.F. Ibrahim, Acta Metall. 27 (1979) 1319-1328.

[15] J.R. Santisteban, M.R. Daymond, J.A. James, L. Edwards, Int. J. Appl. Crystallogr. 39 (2006) 812-825.

[16] O. Muránsky, M.R. Barnett, D.G. Carr, S.C. Vogel, E.C. Oliver, Acta Mater. 58 (2010) 1503-1517.

[17] M.T. Hutchings P.J. Withers T.M. Holden T.Lorentzen Introduction to the Characterization of Residual Stress by Neutron Diffraction CRC Press, ISBN10: 0415310008 ISBN-13: 978-0415310000, 2005, Taylor \& Francis Group 6000, Broken Sound Parkway,NW.

[18] B.H. Toby, J. Appl. Crystallogr. 34 (2001) 210-213.

[19] A.C. Larson, R.B. Von Dreele, in: Los Alamos National Laboratory Report Los Alamos, 2000

[20] S.R. Agnew, C.N. Tomé, D.W. Brown, T.M. Holden, S.C. Vogel, Scr. Mater. 48 (2003) 1003-1008.

[21] D.W. Brown, S.R. Agnew, M.A.M. Bourke, T.M. Holden, S.C. Vogel, C.N. Tomé Mater. Sci. Eng. A 399 (2005) 1-12.

[22] M.A. Gharghouri, G.C. Weatherly, J.D. Embury, J. Root, Philos. Mag. A 79 (1998) 19711695.

[23] P.A. Turner, C.N. Tomé, Acta Metall. Mater. 42 (1994) 4143-4153.

[24] R.A. Lebensohn, C.N. Tomé, Acta Metall. Mater. 41 (1993) 2611-2624.

[25] S. Cai, M.R. Daymond, R.A. Holt, Acta Mater. 60 (2012) 3355-3369.

[26] S. Cai, M.R. Daymond, A.K. Khan, R.A. Holt, E.C. Oliver, J. Nucl. Mater. 393 (2009) 67-76

[27] J.W.L. Pang, T.M. Holden, P.A. Turner, T.E. Mason, Acta Mater. 47 (1999) 373-383.

[28] O. Muránsky, P. Šittner, J. Zrník, E.C. Oliver, Acta Mater. 56 (2008) 3367-3379.

[29] M.R. Daymond, J. Appl. Phys. 96 (2004) 4263-4272.

[30] F. Xu, R.A. Holt, M.R. Daymond, R.B. Rogge, E.C. Oliver, Mater. Sci. Eng. A 488 (2008) 172-185.

[31] F. Xu, R.A. Holt, M.R. Daymond, Acta Mater. 56 (2008) 3672-3687.

[32] J.M. Zuo, J.C. Mabon, Microsc. Microanal. 10 (2004).

[33] D. Bhattacharyya, E.K. Cerreta, R. McCabe, M. Niewczas, G.T.G. III, A. Misra C.N. Tome, Acta Mater. 57 (2009) 305-315.

[34] P.G. Patridge, Metall. Rev. 12 (1967) 169-194.

[35] A. Akhtar, A. Teghtsoonian, Acta Metall. 19 (1971) 655-663. 